\title{
Wogonoside promotes apoptosis and ER stress in human gastric cancer cells by regulating the IRE1 $\alpha$ pathway
}

\author{
QIAN GU, CANHONG ZHU, XI WU, LIANGHUAN PENG, GENYA HUANG and RONG HU \\ Department of Geriatrics, First People's Hospital of Zhenjiang, \\ The Affiliated People's Hospital of Jiangsu University, Zhenjiang, Jiangsu 212000, P.R. China
}

Received April 5, 2020; Accepted August 26, 2020

DOI: $10.3892 /$ etm.2021.9842

\begin{abstract}
Gastric cancer is a disease that occurs in the digestive system of humans and remains a problem in the medical field. Wogonoside, a natural flavonoid, has been reported to exert antitumor effects on various types of tumors. However, the effects of wogonoside on gastric cancer remain elusive. The aim of the present study was to detect whether wogonoside treatment could induce apoptosis and ER stress in gastric cancer cells. In the present study, CCK-8 assay was used to detect the cell viability, Annexin V/PI staining was used to detect the cells apoptosis, western blot analysis and real-time PCR analysis was used to detect the endoplasmic reticulum (ER) stress in the AGS and MKN-45 gastric cancer cell lines. Wogonoside treatment reduced the viability of AGS and MKN-45 cells and induced apoptosis. Furthermore, the expression level of caspase-3 and -9 significantly increased following wogonoside treatment compared with that in non-treated cells, and the protein expression levels of proapoptotic Bax and antiapoptotic Bcl-2 increased and decreased, respectively compared with that in the control group. In addition, the phosphorylated protein expression levels of mitogen-activated protein kinase kinase 5 (ASK1) and JNK increased following wogonoside treatment, and the protein expression levels of tumor necrosis factor receptor-associated factor 2 (TRAF2) and serine/threonine-protein kinase/endoribonuclease IRE1 (IRE1 $\alpha$ ) were also increased following treatment with $50 \mu \mathrm{M}$ wogonoside for $48 \mathrm{~h}$. Furthermore, the interactions between IRE1 $\alpha$, TRAF2 and ASK1 significantly increased following wogonoside treatment, suggesting that wogonoside induced endoplasmic reticulum (ER) stress in the AGS and MKN-45 cell lines. In addition, small interfering
\end{abstract}

Correspondence to: Dr Rong Hu, Department of Geriatrics, First People's Hospital of Zhenjiang, The Affiliated People's Hospital of Jiangsu University, 8 Dianli Road, Zhenjiang, Jiangsu 212000, P.R. China

E-mail: hurongzhenjiang@163.com

Key words: Traditional Chinese Medicine, apoptosis, human gastric cancer, endoplasmic reticulum stress
RNA-mediated silencing of IRE1 $\alpha$ suppressed the activity of the IRE1 $\alpha$-TRAF2-ASK1 complex and prevented wogonoside-induced cell apoptosis. In conclusion, the results of the present study suggested that wogonoside exhibited antitumor activity by inducing ER stress-associated cell death through the IRE1 $\alpha$-TRAF2-ASK1 pathway.

\section{Introduction}

Gastric cancers are one of the most frequent human malignancies, account for nearly $15 \%$ of cancer-related mortalities worldwide between 1970-2007, particularly in developing countries $(1,2)$. Conventional treatments for gastric cancer, such as surgery and chemotherapy, improve the survival of patients with early-stage gastric cancer; however, the prognosis of advanced gastric cancer remains poor due to limited chemosensitivity and multiple severe side effects $(3,4)$. Thus, biochemical and molecular studies are required to develop novel and effective anticancer drugs for treating gastric cancer.

Natural ingredients isolated from plants and modifications of natural molecules have attracted considerable research attention in the past few decades, including the modern anticancer drugs, camptothecin, adriamycin and taxol (5-8). More than ten polyphenolic flavonoids, such as quercetin, catechin, luteolin, rutin and hesperidin, have been reported to possess cytotoxic and antitumor properties (9-11). Their anticancer effects primarily include antioxidant activity, promotion of apoptosis, inhibition of proliferation, migration, invasion and angiogenesis, modulation of signal transduction pathways and reversal of drug resistance $(8,12)$. Evidence has demonstrated that wogonoside (wogonin-7-glucuronide, $\mathrm{C}_{22} \mathrm{H}_{20} \mathrm{O}_{11}$ ), a primary component of the Traditional Chinese Medicine Scutellaria baicalensis, induces apoptosis and cell cycle arrest in multiple types of tumor cells, such as non-small cell lung cancer, hepatocellular carcinoma and chronic myelogenous leukemia cells (13-15). However, whether wogonoside also has antitumor effects in gastric cancer remains unclear.

In the present study, cell viability, apoptosis and endoplasmic reticulum (ER) stress were examined in the AGS and MKN-45 gastric cancer cell lines following wogonoside treatment. The aim of the present study was to investigate the potential pro-apoptotic and pro-ER stress effects of wogonoside on AGS and MKN-45 cells. 


\section{Materials and methods}

Materials and regents. Wogonoside was purchased from Sigma-Aldrich (Merck KGaA) and dissolved in phosphate-buffered saline (PBS; HyClone; Cytiva). The Cell Counting Kit (CCK)-8 Kit assay was purchased from Dojindo Molecular Technologies, Inc. The primary antibodies targeting IRE1 $\alpha$ (cat. no. 3294; rabbit monoclonal), tumor necrosis factor receptor-associated factor 2 (TRAF2; cat. no. 4724; rabbit polyclonal), mitogen-activated protein kinase kinase kinase 5 (ASK; cat. no. 3762; rabbit polyclonal), phosphorylated(p)-ASK (cat. no. 3764; rabbit polyclonal), JNK (cat. no. 4668; rabbit monoclonal), JNK (cat. no. 9252; rabbit polyclonal), DNA damage-inducible transcript 3 protein (CHOP; cat. no. 2895; mouse monoclonal), endoplasmic reticulum chaperone BiP [glucose regulated protein (GRP78); cat. no. 3177; rabbit monoclonal], endoplasmin (GRP94; cat. no. 20292; rabbit monoclonal), cleaved capsase-3 (cat. no. 9664; rabbit monoclonal), capsase-3 (cat. no. 9662; rabbit monoclonal), cleaved capsase-9 (cat. no. 9505; rabbit monoclonal), capsase-9 (cat. no. 9502; rabbit monoclonal), Bcl-2 (cat. no. 4223; rabbit monoclonal), BAX (cat. no. 5023; rabbit monoclonal) and GAPDH (cat. no. 5174; rabbit monoclonal) were purchased from Cell Signaling Technology, Inc. Distilled water was used in all experiments for washing the cells. The Annexin V Apoptosis Detection kit was obtained from BD Biosciences.

Cell culture and transfection. The AGS and MKN-45 cell lines were purchased from the Chinese Academy of Sciences. Immortalized human gastric epithelial GES-1 cell line was purchased from the Department of Biophysics, Institute of Preclinical Medicine, Peking Union Medical University. Cells were cultured in DMEM (Sigma-Aldrich; Merck KGaA) containing $10 \%$ fetal bovine serum (Gibco; Thermo Fisher Scientific, Inc.), $100 \mathrm{U} / \mathrm{ml}$ penicillin $\mathrm{G}$ and $100 \mu \mathrm{g} / \mathrm{ml}$ streptomycin (HyClone; Cytiva). Cells were maintained at $37^{\circ} \mathrm{C}$ in a humidified incubator with $5 \% \mathrm{CO}_{2}$. Short tandem repeat DNA profiling analysis was used for cell line authentication. Scrambled small interfering (si) RNA and IRE1 $\alpha$ siRNA were designed and synthesized by Sangon Biotech Co.,Ltd. and transfected with Lipofectamine ${ }^{\circledR}$ RNAiMAX (Invitrogen; Thermo Fisher Scientific, Inc.) The siRNA primer sequence of IRE1 $\alpha$ was as follows: forward, 5'-CCATCGAGCTGTGTGCAG-3' and reverse, 5'-TGTTGAGGGAGTGGAGGTG-3'. A total of $5 \mu \mathrm{l}$ of $50 \mathrm{nM}$ siRNAs were added into $250 \mu \mathrm{l}$ Opti-MEM medium (Invitrogen; Thermo Fisher Scientific, Inc.). In addition, $0.2 \mu \mathrm{M}$ control-siRNA (cat no. sc-36869; Santa Cruz Biotechnology, Inc.) was used for the controls. The siRNA solutions were transfected into the cells using Lipofectamine ${ }^{\circledR}$ 2000 (Invitrogen; Thermo Fisher Scientific, Inc.) according to the manufacturer's instructions. The transfection efficiency was analysed $48 \mathrm{~h}$ post transfection.

CCK- 8 assay. The CCK- 8 assay was used according to the manufacturer's protocol. The AGS, MKN-45 and GES-1 cell lines were plated at $15 \times 10^{4}$ cells/well with $2 \mathrm{ml}$ medium in to reach a confluence of $70-90 \%$. Before the cell viability assay, cells were seeded in 96-well plates and treated with $0,2.5$, $5,10,25,50$ and $75 \mu \mathrm{M}$ of wogonoside for $48 \mathrm{~h}$, or treated with wogonoside $(50 \mu \mathrm{M})$ for varying treatment times $(0,6$,
$12,24,48,72$ and $96 \mathrm{~h})$. For the cell viability assay, $10 \mu \mathrm{l}$ CCK-8 solution was added to each well containing $100 \mu \mathrm{l}$ medium (volume ratio, 10\%) for different doses or varying time points; air bubbles were avoided. The plates were incubated for an additional $1-4 \mathrm{~h}$ at $37^{\circ} \mathrm{C}$ in the incubator. The absorbance at $450 \mathrm{~nm}$ was measured using a microplate reader (BioTek Instruments, Inc.).

Annexin V/PI staining. Cell apoptosis was determined using the FITC Annexin V Apoptosis Detection kit (BD Biosciences). After treatment with $50 \mu \mathrm{M}$ wogonoside for $48 \mathrm{~h}$, cells $\left(\sim 1 \times 10^{5}\right.$ cells) were washed and resuspended in $100 \mu 1$ $1 \mathrm{X}$ binding buffer. Following which, $5 \mu \mathrm{l}$ Annexin V-FITC and $5 \mu \mathrm{l}$ PI was added to $100 \mu \mathrm{l}$ of the cell suspension and incubated for 15-20 min at room temperature in the dark. The stained cells were diluted with the binding buffer $(400 \mu \mathrm{l})$ without washing and analysed using BD FACSVerse ${ }^{\mathrm{TM}}$ flow cytometer (BD Biosciences) and the FlowJo ${ }^{\mathrm{TM}}$ VX10 software (FlowJo LLC). All the apoptotic cells contained early apoptotic cells (Annexin V-positive and PI negative), as well as late apoptotic and necrotic cells (Annexin V-positive and PI-positive).

Immunoprecipitation. Cells were harvested and lysed with immunoprecipitation lysis buffer (Pierce; Thermo Fisher Scientific, Inc.), containing proteinase/phosphatase inhibitor (Sigma-Aldrich; Merck $\mathrm{KGaA}$ ) for $2 \mathrm{~h}$ at $4^{\circ} \mathrm{C}$. The protein concentrations of the samples were determined using a BCA Protein Assay kit (Pierce; Thermo Fisher Scientific, Inc.) and adjusted to $1 \mathrm{mg} / \mathrm{ml}$ with lysis buffer. Samples were incubated with anti-IRE1 $\alpha$ antibody $(1: 200)$ or rabbit $\operatorname{IgG}(1: 2,000)$ overnight $(12-16 \mathrm{~h})$ at $4^{\circ} \mathrm{C}$ with gentle orbital rotation $(8 \mathrm{rpm})$. Then, $50 \mu 1$ protein A-Sepharose beads (Thermo Fisher Scientific, Inc.) was added to the samples and incubated for a further $12 \mathrm{~h}$ at $4^{\circ} \mathrm{C}$. The beads were then washed three times with ice-cold PBS and separated with $10 \%$ SDS-PAGE followed by western blot analysis.

Western blot analysis. The AGS cells and MKN-45 cell lines were harvested and lysed in cell lysate buffer (TakaraBio, Inc.) for $30 \mathrm{~min}$ and subsequently centrifuged in a microcentrifuge at $12,000 \mathrm{x} \mathrm{g}$ for $15 \mathrm{~min}$ at $4^{\circ} \mathrm{C}$. Proteins were quantified using a BCA Protein Assay kit (Pierce; Thermo Fisher Scientific, Inc.). Proteins $(30 \mu \mathrm{g})$ were separated with $10 \%$ SDS-PAGE after heating at $37^{\circ} \mathrm{C}$ for $5 \mathrm{~min}$ in $1 \mathrm{X}$ SDS loading buffer and transferred to a polyvinylidene difluoride membrane (EMD Millipore) at $280 \mathrm{~mA}$ for $2.5 \mathrm{~h}$. After blocking with $5 \%$ skimmed milk at room temperature for $2 \mathrm{~h}$, the membranes were incubated with cleaved caspase- 3 $(1: 1,000)$, caspase-3 $(1: 1,000)$, cleaved caspase-9 $(1: 1,000)$, caspase-9 (1:1,000), Bcl-2 (1:1,000), Bax (1:1,000), IRE1 $\alpha$ $(1: 1,000)$, TRAF2 $(1: 1,000)$, ASK $(1: 1,000), p-A S K ~(1: 1,000)$, p-JNK $(1: 1,000)$, JNK $(1: 1,000)$ or GAPDH $(1: 2,000)$ primary antibodies overnight at $4^{\circ} \mathrm{C}$ and subsequently incubated with horseradish peroxidase-conjugated anti-rabbit IgG secondary antibody (cat. no. 7074; Cell Signaling Technology, Inc.) at room temperature for $2 \mathrm{~h}$. The protein bands were visualized using an enhanced chemiluminescence reagent (Thermo Fisher Scientific, Inc.). ImageJ 1.53 software (National Institutes of Health) was used to analyse the mean grey values of each 
band. The relative protein expression levels were calculated using GAPDH as the loading control, and phosphorylation levels were analyzed by comparing the values with the total levels of the corresponding proteins $(16,17)$.

Reverse transcription-quantitative (RT-q) PCR. Total mRNA was extracted from the AGS and MKN-45 cell lines using TRIzol $^{\circledR}$ (Thermo Fisher Scientific, Inc.). RT was performed using a kit with gDNA Eraser (Takara Bio, Inc.) following the manufacturer's protocol. Relative mRNA expression levels of CHOP, GPR78, and GPR94 were measured using a SYBR Premix Ex TaqII kit (Takara Bio, Inc.) on a 7500 qPCR system (Applied Biosystems; Thermo Fisher Scientific, Inc.). The thermocycling conditions were as follows: Initial denaturation at $95^{\circ} \mathrm{C}$ for $10 \mathrm{~min}$; followed by 40 cycles of $95^{\circ} \mathrm{C}$ for $1 \mathrm{~min}$ and $60^{\circ} \mathrm{C}$ for $1 \mathrm{~min}$. Fold changes were calculated using the $2^{-\Delta \Delta \mathrm{Cq}}$ method (18). Actin was used as the reference gene. The primers used for RT-qPCR were as follows: CHOP forward, 5'-AGAACAGCCGTTACTTCAGGA-3' and reverse, 5'-CCG CTGGTAGGAGGTTTTAGAG; GPR78 forward, 5'-CCA CCAGGAAGATTGGCATTG and reverse, 5'-CTTGCTGTA GGTCAGGCACT; GPR94 forward, 5'-AATACTTTGGCT CTGTGGGT-3' and reverse, 5'-AACGACACACAAAAGCTC T; actin forward, 5'-GAATCAATGCAAGTTCGGTTCC-3' and reverse, 5'-TCATCTCCGCTATTAGCTCCG-3'.

Statistical analysis. Data are presented as the mean \pm SD of at least three independent experiments. Comparisons between two groups were performed using an unpaired Student's t-test. Differences between $>2$ groups were determined using one-way ANOVA followed by Bonferroni's post hoc test. GraphPad Prism 8.0 (GraphPad Software, Inc.) and SPSS 25.0 software (IBM Corp.) were used for data analysis. $\mathrm{P}<0.05$ was considered to indicate a statistically significant difference.

\section{Results}

Wogonoside reduces cell viability of the AGS and MKN-45 cell lines. Fig. 1A shows the molecular structure of wogonoside. To investigate whether wogonoside affected cancer cell viability, the AGS and MKN-45 cell lines were treated with varying concentrations of wogonoside $(0,2.5,5,10,25,50$ and $75 \mu \mathrm{M})$ for $48 \mathrm{~h}$ and cell viability was then evaluated. The results of the CCK- 8 assay demonstrated that wogonoside significantly reduced the cell viability of the AGS and MKN-45 cell lines at concentrations $\geq 10 \mu \mathrm{M}$ (Fig. 1B and C), with $50 \mu \mathrm{M}$ showing the most effective inhibitory effect of cell viability. Subsequently, the AGS and MKN-45 cell lines were treated with wogonoside $(50 \mu \mathrm{M})$ for varying treatment times $(0,6,12$, 24, 48, 72 and $96 \mathrm{~h}$ ). The results demonstrated that wogonoside significantly reduced cell viability (Fig. 1D and E). The gastric epithelial immortalized cell line (GES-1) was used as a control to evaluate the effect of wogonoside. No significant difference was observed in the cell viability of GES-1 cells by wogonoside treatment at varying concentrations for $48 \mathrm{~h}$ (Fig. 1F). In addition, wogonoside treatment did not affect the cell cycle of the GES-1 cell line (data not shown)

Wogonoside induces apoptosis in the AGS and MKN-45 cell line. To determine whether the reduction in cell viability was caused by cell apoptosis, Annexin V/PI staining was performed to evaluate the apoptotic rate of AGS and MKN-45 cells following treatment with $50 \mu \mathrm{M}$ wogonoside. The proportion of Annexin V-labelled apoptotic cells significantly increased following treatment with $50 \mu \mathrm{M}$ wogonoside for $48 \mathrm{~h}$ compared with that in non-treated cells (Fig. 1H and I). However, apoptosis of GES-1 cells was not affected by treatment with $50 \mu \mathrm{M}$ wogonoside (Fig. 1G).

In addition, the levels of cleaved caspases and the protein expression levels of apoptosis-related proteins were determined. The results demonstrated that the levels of cleaved caspase- 3 and -9 significantly increased when the AGS and MKN-45 cells were treated with $50 \mu \mathrm{M}$ wogonoside compared with that in the control group (Fig. 2A-D). In addition, compared with that in the control group, wogonoside treatment significantly downregulated the protein expression levels of Bcl-2 and upregulated the expression levels of Bax, suggesting that wogonoside induced apoptosis in the AGS and MKN-45 cell lines (Fig. 2A-D). Thus, these results indicated that high concentrations of wogonoside induced apoptosis in the AGS and MKN-45 cell lines.

Wogonoside induces ER stress in the AGS and MKN-45 cell lines. In recent years, ER stress has emerged as a crucial instigator of the intrinsic apoptotic pathway in multiple cell types, including gastric cancer cells $(19,20)$. To determine the involvement of ER stress in wogonoside-induced apoptosis of the AGS and MKN-45 cell lines, the activation of the ER stress pathway was determined. Compared with that in the control group the exposure to wogonoside significantly increased the protein and mRNA expression levels of CHOP, a known ER stress-related marker (21), and GRP78 and GPR94 (Fig. 3A-F), suggesting that ER stress was initiated by wogonoside treatment. In addition, compared with that in the control group the phosphorylation levels of JNK and ASK and the protein expression levels of TRAF2 and IRE1 $\alpha$ were significantly increased by $50 \mu \mathrm{M}$ wogonoside (Fig. 3G-J) thus, suggesting that the JNK signaling pathway was involved in the response to wogonoside-induced apoptosis and ER stress.

Wogonoside induces apoptosis by initiating ER stress via the IRE1 $\alpha$-TRAF2-ASK1 pathway. In response to ER stress, unfolded or misfolded proteins that accumulate in the ER leads to the unfolded protein response (UPR) (22). The ER stress sensor, IRE1 $\alpha$ initiates the UPR by recruiting TRAF2 to form the TRAF2-ASK1-IRE1 $\alpha$ complex, further activating the JNK signaling pathway $(23,24)$. To investigate the mechanism by which wogonoside initiates ER stress and apoptosis, coimmunoprecipitation analyses revealed that the physical interactions within the TRAF2-ASK-IRE1 $\alpha$ complex were enhanced following wogonoside treatment (Fig. 4A and B). In addition, siRNA-mediated knockdown of the UPR transducer IRE1 $\alpha$ was performed in the AGS and MKN-45 cell lines. As shown in Fig. S1, the protein levels of IRE1 $\alpha$ decreased both in AGS and MKN-45 cell lines after siRNA-mediated knockdown. The wogonoside-induced upregulation of IRE1 $\alpha$ was significantly inhibited by $\sim 85 \%$ in the AGS and MKN-45 cell lines treated with siRNA-targeting IRE1 $\alpha$ for $48 \mathrm{~h}$ (Fig. 4C-4F). The inactivation of IRE1 $\alpha$ by RNA interference inhibited wogonoside-induced activation of ASK and 
A

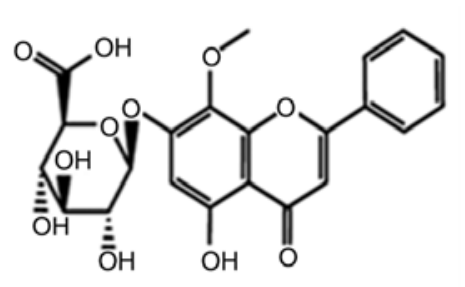
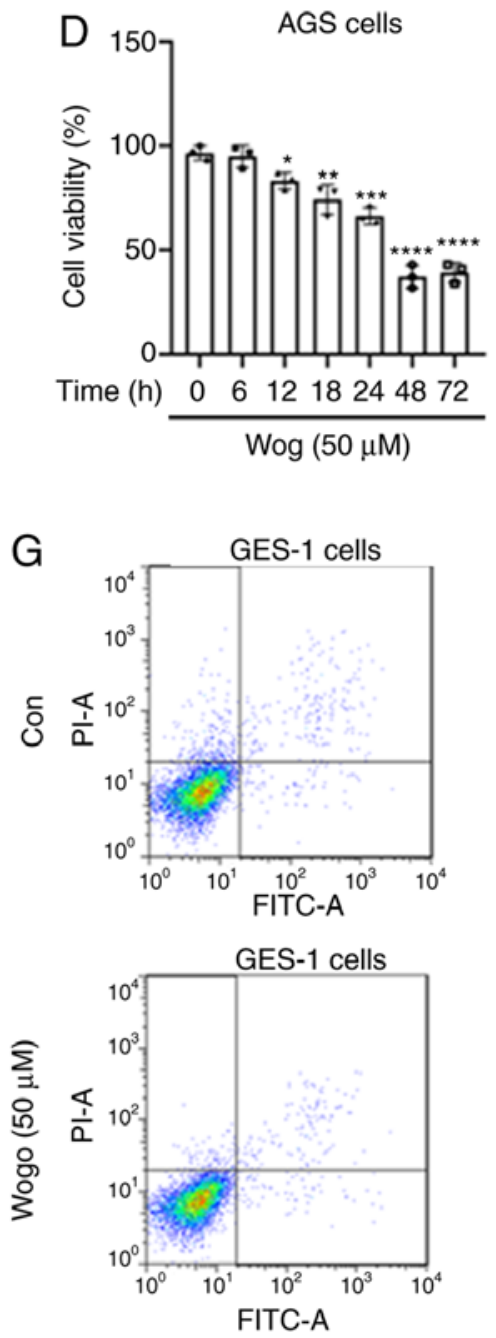

GES-1 cells

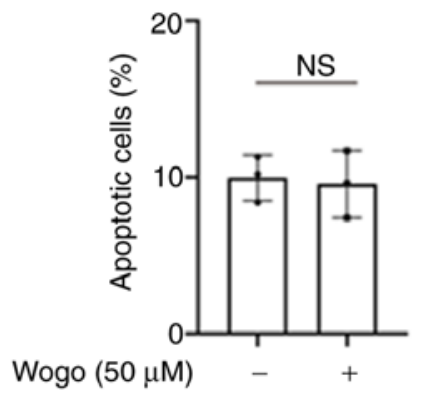

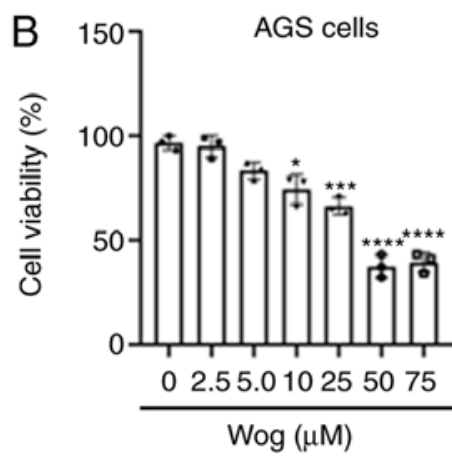
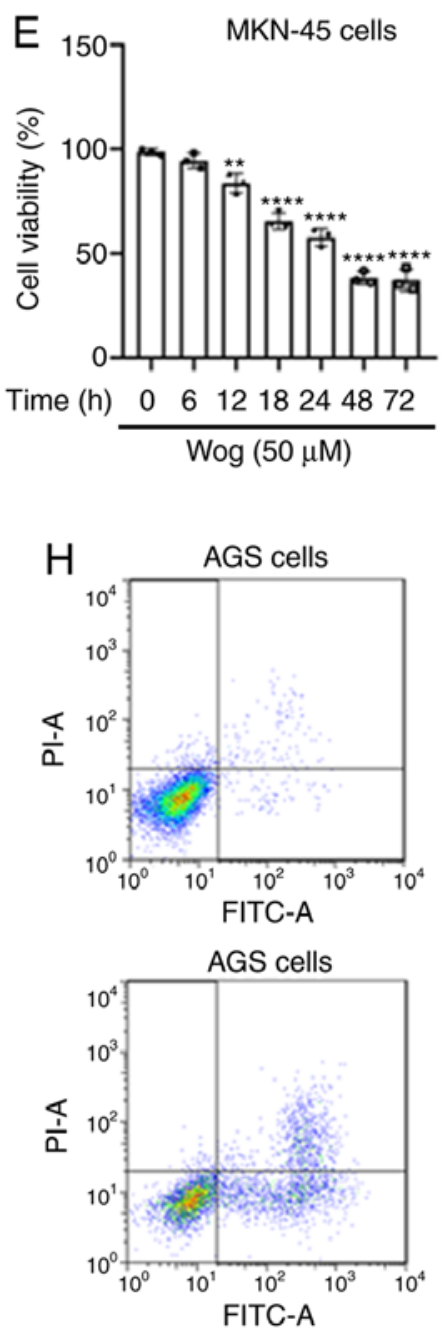

AGS cells

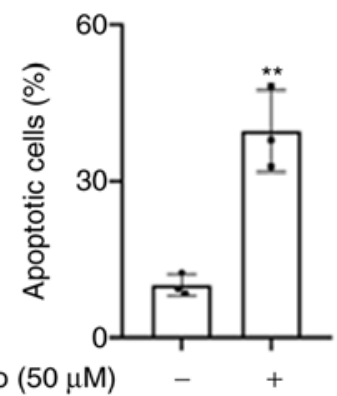

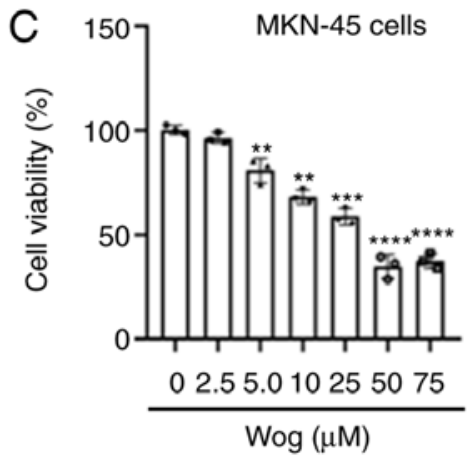
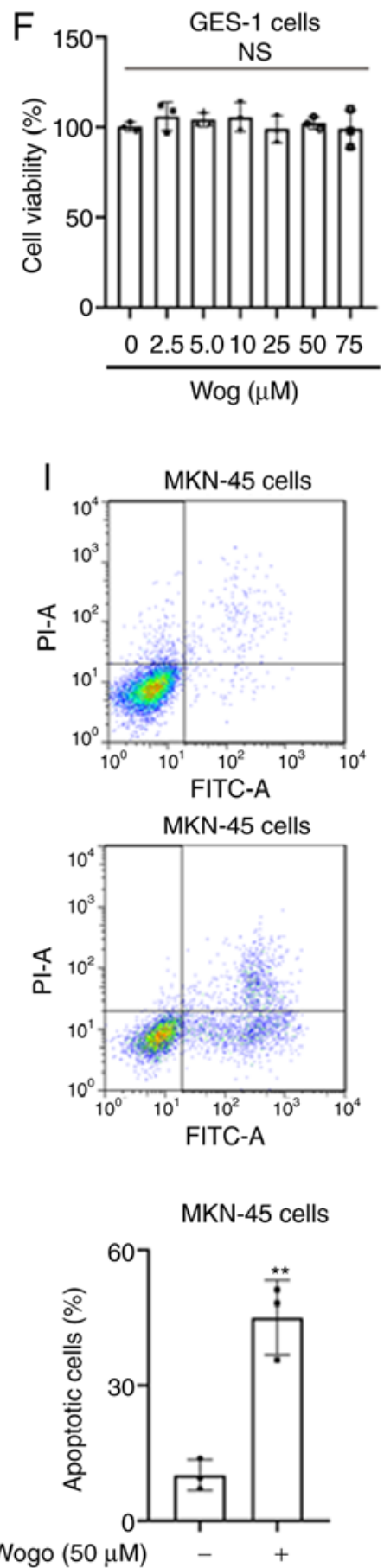

Figure 1. Wogonoside decreases cell viability of AGS cells and MKN-45 cells. (A) Molecular structure of wogonoside. The AGS and MKN-45 cell lines were treated with (B and C) different concentrations of wogonoside and at (D and E) different periods of time. (F) GES-1 cells were exposed to different concentrations of wogonoside for $48 \mathrm{~h}$. Cell viability (B, C, D and E) and apoptosis (G, H and I) were evaluated using Cell Counting Kit-8 assay and Annexin V staining, respectively in the AGS, MKN-45 and GES-1 cell lines. ${ }^{*} \mathrm{P}<0.05,{ }^{* *} \mathrm{P}<0.01,{ }^{* * *} \mathrm{P}<0.001,{ }^{* * * *} \mathrm{P}<0.0001$, ${ }^{\text {ns }} \mathrm{P}>0.05$. Wog, wogonoside; NS, non-significant. 
A

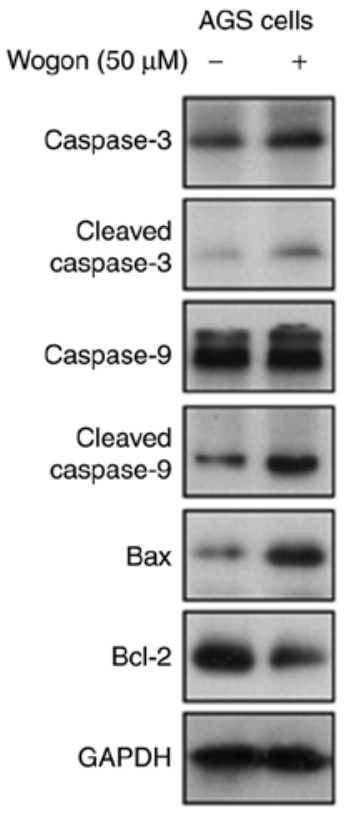

C

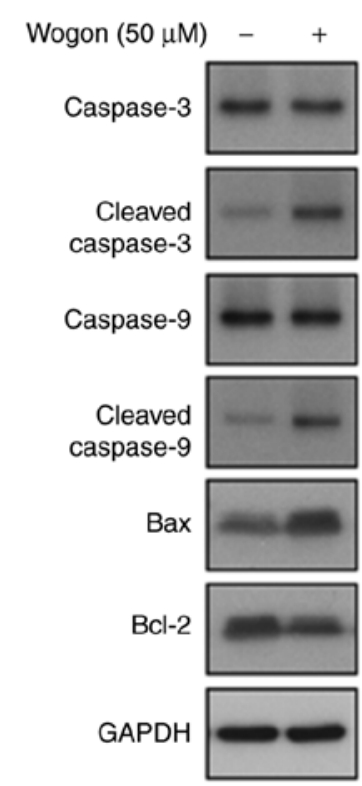

B $\bullet$ Con

$\circ \operatorname{Wog}(50 \mu \mathrm{M})$

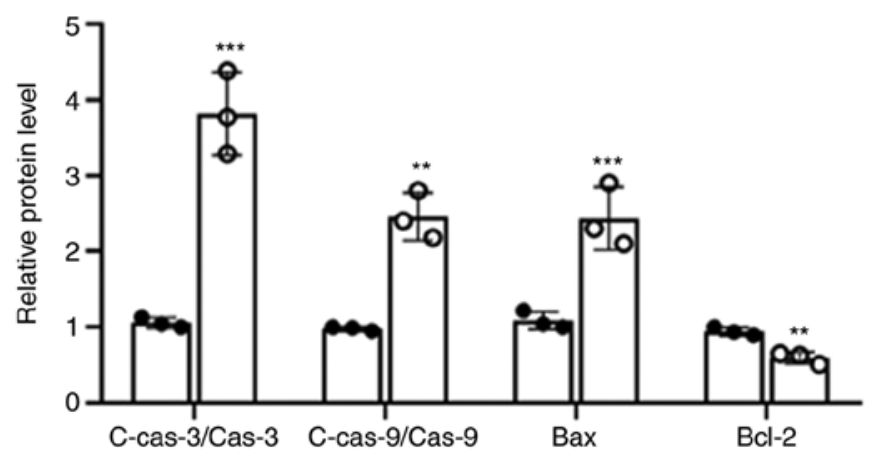

D $\quad$ Con

- $\operatorname{Wog}(50 \mu \mathrm{M})$

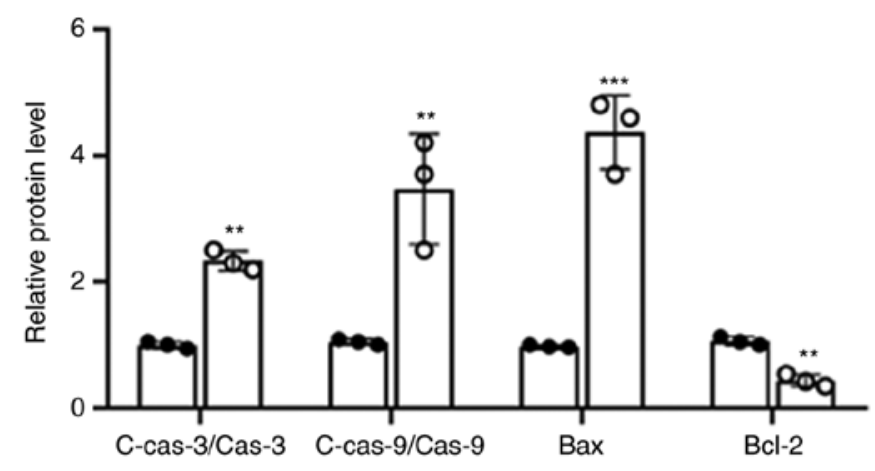

Figure 2. Wogonoside induces apoptosis in the AGS and MKN-45 cell lines. The protein expression levels of caspase-3 and -9, Bax, Bcl-2 and GAPDH were determined using western blot analysis in (A) AGS and (C) MKN-45 cell lines following $50 \mu \mathrm{M}$ wogonoside treatment for $48 \mathrm{~h}$. Changes in relative protein expression levels of caspase-3 and -9 , Bax and Bcl-2 were determined using densitometry in the (B) AGS and (D) MKN-45 cells. ${ }^{* * *} \mathrm{P}<0.01$ vs. con; ${ }^{* * * *} \mathrm{P}<0.001$ vs. con. Wog, wogonoside; con, control, c; cleaved; cas, capase.

JNK, suggesting that IRE1 $\alpha$ activation was required for JNK activation (Fig. 4C-F). In addition, wogonoside-induced cell viability inhibition and apoptosis of the AGS and MKN-45 cell lines were also prevented by IRE1 $\alpha$ interference (Figs. 4G-J and S2) these findings suggested that the activation of the IRE1 $\alpha$-TRAF2-ASK1 signaling pathway was required for wogonoside-induced apoptosis in the AGS and MKN-45 cell lines.

\section{Discussion}

Traditional Chinese Medicines, including thousands of plants and herbs, have antitumor properties with low toxicity and side effects (25). Among them, Scutellaria baicalensis is well-known for its antimicrobial activity and anti-inflammatory effects. Several chemical compounds have been extracted from Scutellaria baicalensis, including baicalein, baicalin, wogonin and oroxylin A (26). Wogonin is recognized as the primary component responsible for the therapeutic effects of Scutellaria baicalensis (27). The antitumor effects of wogonin, including induction of cell cycle arrest, promotion of apoptosis and increase in drug sensitivity, have been reported in cervical cancer cell lines (28-30). Wogonoside, a glycoside of wogonin, is more stable in vivo. The effect of wogonoside has been previously studied in various types of cancer, such as breast, colon, and lung cancers (31). However, to the best 


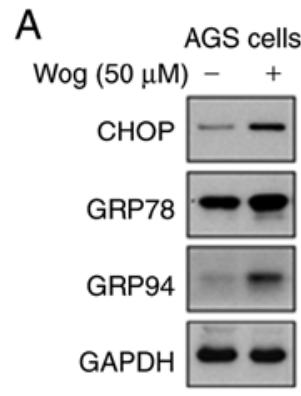

D MKN-45 cells

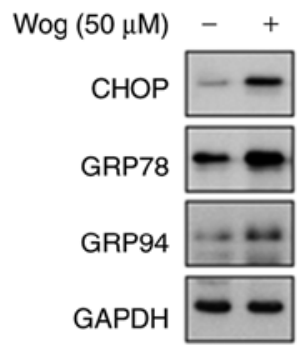

$$
\text { B } \quad \text { Con AG }
$$

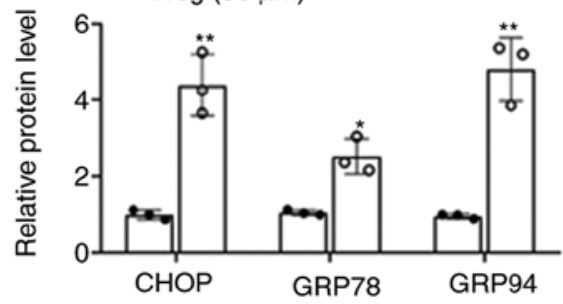

\section{E}

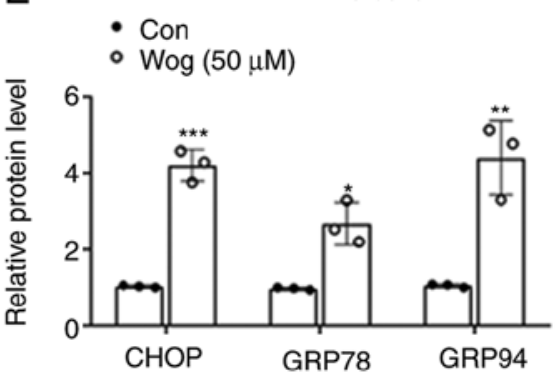

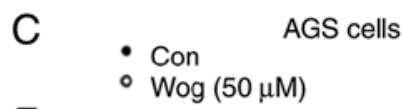

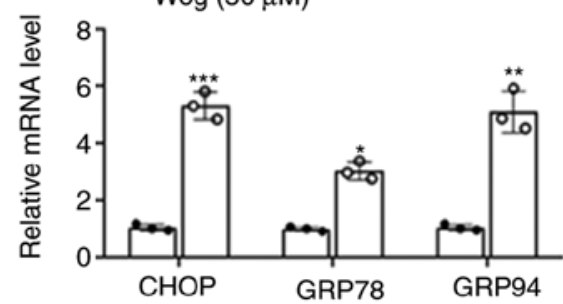

$\mathrm{F}$

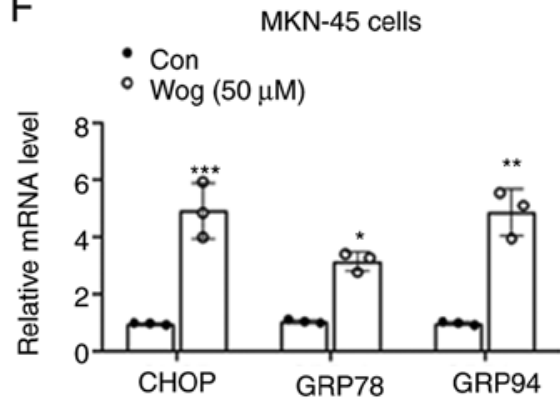

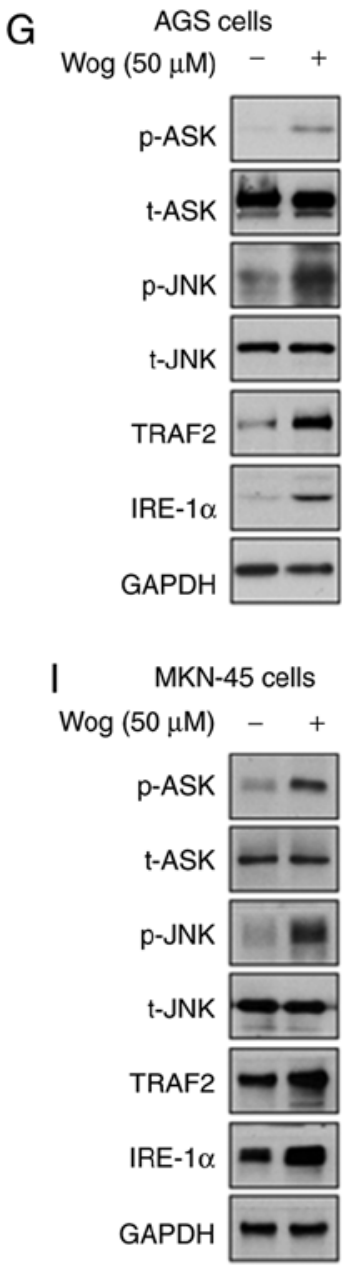
$\mathrm{H}$
- Con
AGS cells
- $\operatorname{Wog}(50 \mu \mathrm{M})$

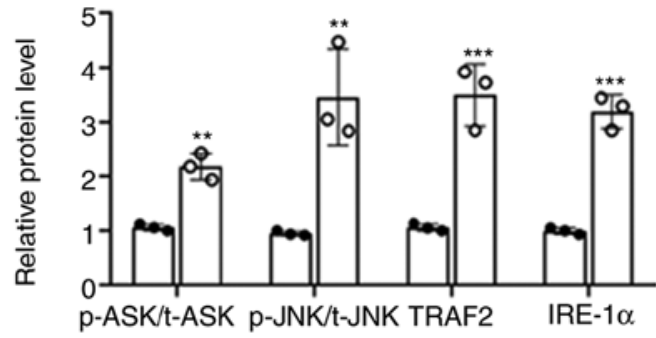

- Con

MKN-45 cells

- Wog $(50 \mu \mathrm{M})$

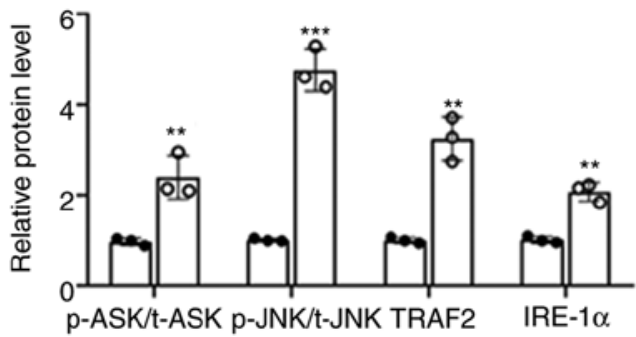

Figure 3. Wogonoside activates endoplasmic reticulum stress and increases p-ASK and p-JNK protein expression levels in the AGS and MKN-45 cell lines. The protein expression levels of CHOP, GRP78 and GRP94 were measured in the (A) AGS and (D) MKN-45 cell lines following $50 \mu$ M wogonoside treatment for $48 \mathrm{~h}$. Changes in relative protein expression levels of CHOP, GRP78 and GRP94 were determined using densitometry in the (B) AGS and (E) MKN-45 cell lines. Relative mRNA expression levels of CHOP, GRP78 and GRP94 were measured in the (C) AGS and (F) MKN-45 cell lines following $50 \mu \mathrm{M}$ wogonoside treatment for $48 \mathrm{~h}$. The protein expression levels of p-ASK, t-ASK, p-JNK, t-JNK, TRAF2, IRE1 $\alpha$ and $\beta$-actin were determined using western blot analysis in (G) AGS and (I) MKN-45 cell lines following $50 \mu \mathrm{M}$ wogonoside treatment for $48 \mathrm{~h}$. Changes in relative protein expression levels of p-ASK, p-JNK TRAF2 and IRE1 $\alpha$ were determined using densitometry in (H) AGS and (J) MKN-45 cell lines. ${ }^{*} \mathrm{P}<0.05$ vs. con; ${ }^{* *} \mathrm{P}<0.01$ vs. con; ${ }^{* * *} \mathrm{P}<0.001$ vs. con. Wog, wogonoside; con, control. t, total; ASK, mitogen-activated protein kinase kinase kinase 5; TRAF2, tumour necrosis factor receptor-associated factor 2; IRE1 $\alpha$, serine/threonine-protein kinase/endoribonuclease IRE1; CHOP, DNA damage-inducible transcript 3 protein; GRP, glucose-regulated protein; GRP78, endoplasmic reticulum chaperone BiP; GRP94, endoplasmin; p, phosphorylated. 

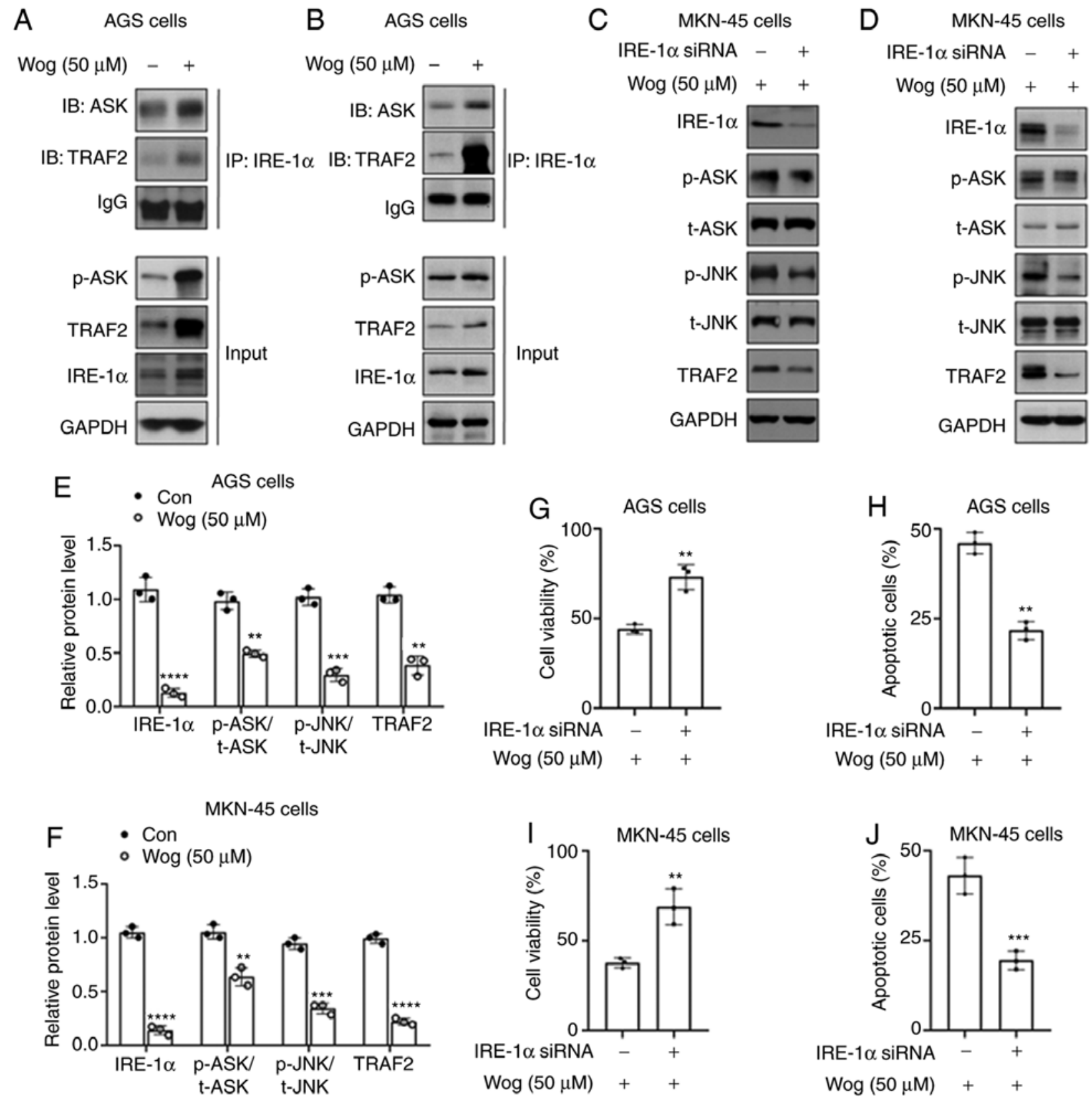

Figure 4. Wogonoside induces apoptosis via IRE1 $\alpha$ in the AGS and MKN-45 cell lines. (A) Interaction between IRE1 $\alpha$ and TRAF2/ASK was determined using immunoprecipitation in (A) AGS and (B) MKN-45 cell lines following $50 \mu \mathrm{M}$ wogonoside treatment for $48 \mathrm{~h}$. Cells were treated with $50 \mu \mathrm{M}$ wogonoside for $48 \mathrm{~h}$ following transfection with or without IRE1 $\alpha$ siRNA and the protein expression levels of p-ASK, ASK, p-JNK, t-JNK TRAF2 and IRE1 $\alpha$ were measured using western blot analysis of whole cell lysates in the (C) AGS and (D) MKN-45 cell lines. The protein expression levels of IRE1 $\alpha$, TRAF2 and ASK relative to GAPDH levels were calculated using densitometry in the (E) AGS and (F) MKN-45 cell lines. Cells transfected with or without siRNA were treated with $50 \mu \mathrm{M}$ wogonoside for $48 \mathrm{~h}$. The effects of siRNA-mediated IRE1 $\alpha$ interference on wogonoside-induced decrease of cell viability in (G) AGS and (I) MKN-45 cell lines using Cell Counting Kit- 8 assay. The effects of siRNA-mediated IRE1 $\alpha$ interference on wogonoside-induced increase of apoptosis in the (H) AGS and (J) MKN-45 cell lines. ${ }^{* * *} \mathrm{P}<0.01$ vs. con; ${ }^{* * *} \mathrm{P}<0.001$ vs. con; ${ }^{* * * * *} \mathrm{P}<0.0001$ vs. con. Wog, wogonoside; con, control. t, total; ASK, apoptosis signal-regulating kinase; TRAF2, tumour necrosis factor receptor-associated factor 2; IRE1 $\alpha$, serine/threonine-protein kinase/endoribonuclease IRE1; si, small interfering; p, phosphorylated.

of our knowledge, no study has been conducted on the role of wogonoside in human gastric cancer, or the effect of wogonoside on ER stress activation and the IRE1 $\alpha$-TRAF2-ASK1 signaling pathway.

Apoptosis is a central mechanism for regulating cell death and survival and the main basis for current tumor treatment strategies (32). Caspases comprise a family of cysteine proteases that serve essential roles in apoptosis (32). Caspase-3 is a downstream apoptosis executor and activated by caspase- 9 (33). Notably, the results of the present study demonstrated that wogonoside increased the protein expression level of caspase- 3 and -9 . The release of cytochrome $c$ from the mitochondria into the cytoplasm is another characteristic feature of apoptosis and has been considered an initiator for the activation of the caspase cascades (34). The released cytochrome $c$ interacts with apoptotic protease activating factor 1 in the cytosol, leading to the proteolytic activation of caspase- 9 (35). The activated caspase- 9 further 
activates caspase- 3 by proteolytic cleavage, which then triggers apoptotic cell death (36). The Bcl-2 family is known for regulating the release of cytochrome $c$. The proapoptotic Bcl-2 family members, Bax and Bcl-2 homologous antagonist/killer (Bak), promote cytochrome $c$ release, whereas antiapoptotic Bcl-2 prevents the release of cytochrome $c$ by binding and inhibiting Bax and Bak (37,38). The results of the present study demonstrated that $\mathrm{Bcl}-2$ protein expression level was decreased, while Bax was increased after woginoside treatment, suggesting that the mitochondrial pathway was activated in wogonoside-induced apoptosis in the AGS and MKN-45 cell lines.

Previous studies have demonstrated that ER stress was involved in apoptosis in several types of cancer cells, including gastric cancer $(19,20)$. The ER is a highly dynamic membranous system that regulates cellular $\mathrm{Ca}^{2+}$ signaling and protein folding in mammalian cells (39). ER dysfunction is induced by various stimuli, such as nutrient deprivation, hypoxia and insulin resistance, leading to the accumulation of unfolded or misfolded proteins, ultimately causing ER stress and UPR $(40,41)$. Evidence has demonstrated that the multifunctional transcription factor CHOP was activated in ER stress and promoted apoptosis (42). Notably, the results of the present study demonstrated that CHOP expression was significantly increased in the gastric cancer cell lines following wogonoside treatment. GRP78 and GRP94, commonly used as canonical biomarkers of ER stress, are known to serve essential roles in protein folding, sorting and secretion (43). The results of the present study demonstrated that the protein expression levels of GRP78 and GRP94 were elevated in AGS and MKN-45 cells following treatment with wogonoside for $48 \mathrm{~h}$. The aforementioned findings suggested that the ER stress response was triggered and involved in wogonoside-induced apoptosis of the AGS and MKN-45 cell lines.

IRE1 $\alpha$ is well-known to act as the primary ER stress transducer and serves a crucial role in regulating ER stress and UPR $(44,45)$. The apoptotic IRE1 $\alpha$ signaling pathway is triggered during severe or prolonged ER stress. The activated IRE1 $\alpha$ interacts with the scaffold molecule TRAF2 and subsequently recruits ASK1. Then, the IRE1 $\alpha$-TRAF2-ASK1 complex activates JNK, which participates in cell apoptosis by regulating the phosphorylation and activation of the Bcl-2 family proteins $(44,45)$. The results of the present study demonstrated that IRE1 $\alpha$, TRAF2, p-ASK1 and p-JNK protein expression levels were significantly upregulated in the AGS and MKN-45 cell lines following wogonoside exposure, suggesting the activation of proapoptotic signaling. In addition, the protein interactions in the IRE1 $\alpha$-TRAF2-ASK1 complex and the activation of the ASK1-JNK signaling pathway were markedly increased following wogonoside treatment. Furthermore, wogonoside-induced cell death was prevented in the IRE1 $\alpha$-knockdown AGS and MKN-45 cell lines, suggesting that IREl $\alpha$ was essential for wogonoside-induced activation of ER stress and cell apoptosis.

Previous studies have reported the oral bioavailability of flavonoids included wogonoside in vivo and in vitro $(46,47)$. The local recycling of wogonoside is performed in the upper small intestine $(46,47)$. There were a number of limiting factors of oral bioavailability for flavonoids in the human intestinal Caco-2 cell line, including poor membrane permeability, significant efflux and efficient intestinal metabolism by conjugation (48). In addition, different preparation methods also affected the pharmacokinetic characteristics of wogonoside and active constituents in the wogonoside-berberine complex (49). The formation of the wogonoside-berberine complex serves a significant role in the bioavailability enhancement of flavonoids and other pharmacologically active constituents (46). For example, Coptis Chinensis (CC) may decrease the bioavailability of wogonoside in Radix Scutellariae following intragastric gavage administration in rats and the mechanism was associated with CC decreasing the transport of flavonoid aglycones from the mucosa side to the serosal side and the hydrolyzation of flavonoids by inhibiting intestinal flora $(49,50)$. Notably, in future studies the effect of wogonoside on tumor growth in vivo, as well as improving the bioavailability of wogonoside will be investigated.

In conclusion, the results of the present study demonstrated that wogonoside treatment decreased cell viability and promoted apoptosis in the AGS and MKN-45 cell line. The IRE1 $\alpha$-TRAF2-ASK1 signaling pathway could serve key roles in ER stress signal transduction and wogonoside-induced apoptosis. Furthermore, new insights into the mechanisms by which wogonoside triggered cell death in human gastric cancer cells were found. There were several limitations to the present study. For example, the proapoptotic effect of wogonoside in human gastric cancer cells was only investigated. Whether wogonoside could inhibit the carcinogenesis of gastric cancer in animal models requires verification. In addition, the exact mechanism of wogonoside in gastric cancer initiation and/or progression is unknown; therefore, animal models and clinical studies are required to elucidate the therapeutic value of wogonoside in gastric cancer.

\section{Acknowledgements}

Not applicable.

\section{Funding}

The present study was supported by the Zhenjiang Science and Technology Committee (grant no. SH2018061).

\section{Availability of data and materials}

The datasets used and/or analysed during the current study are available from the corresponding author on reasonable request.

\section{Authors' contributions}

RH and QG contributed to the study design, data collection, statistical analysis, data interpretation and the manuscript preparation. $\mathrm{CZ}, \mathrm{XW}$ and $\mathrm{LP}$ contributed to the data collection and the statistical analysis. GH contributed to the data collection, statistical analysis and manuscript preparation. All authors read and approved the final manuscript.

\section{Ethics approval and consent to participate}

Not applicable. 


\section{Patient consent for publication}

Not applicable.

\section{Competing interests}

The authors declare that they have no competing interests.

\section{References}

1. Ashktorab H, Kupfer SS, Brim H and Carethers JM: Racial disparity in gastrointestinal cancer risk. Gastroenterology 153: 910-923, 2017.

2. Alyami M, Hubner M, Grass F, Bakrin N, Villeneuve L, Laplace N, Passot G, Glehen O and Kepenekian V: Pressurised intraperitoneal aerosol chemotherapy: Rationale, evidence, and potential indications. Lancet Oncol 20: e368-e377, 2019.

3. Lau HCH, Kranenburg O, Xiao H and Yu J: Organoid models of gastrointestinal cancers in basic and translational research. Nat Rev Gastroenterol Hepatol 17: 203-222, 2020.

4. Padmanabhan N, Ushijima T and Tan P: How to stomach an epigenetic insult: The gastric cancer epigenome. Nat Rev Gastroenterol Hepatol 14: 467-478, 2017.

5. Hirchaud F, Hermetet F, Ablise M, Fauconnet S, Vuitton DA Prétet JL and Mougin C: Isoliquiritigenin induces caspasedependent apoptosis via downregulation of HPV16 E6 expression in cervical cancer Ca Ski cells. Planta Med 79: $1628-1635,2013$

6. Krifa M, Alhosin M, Muller CD, Gies JP, Chekir-Ghedira L, Ghedira K, Mély Y, Bronner C and Mousli M: Limoniastrum guyonianum aqueous gall extract induces apoptosis in human cervical cancer cells involving $\mathrm{p} 16^{\mathrm{INK} 4 \mathrm{~A}}$ re-expression related to UHRF1 and DNMT1 down-regulation. J Exp Clin Cancer Res 32: 30, 2013.

7. Koppikar SJ, Choudhari AS, Suryavanshi SA, Kumari S, Chattopadhyay S and Kaul-Ghanekar R: Aqueous cinnamon extract (ACE-c) from the bark of Cinnamomum cassia causes apoptosis in human cervical cancer cell line $(\mathrm{SiHa})$ through loss of mitochondrial membrane potential. BMC Cancer 10: 210, 2010.

8. Weng CJ and Yen GC: Flavonoids, a ubiquitous dietary phenolic subclass, exert extensive in vitro anti-invasive and in vivo anti-metastatic activities. Cancer Metastasis Rev 31: 323-351, 2012.

9. Deng X, Zhao X, Lan Z, Jiang J, Yin W and Chen L: Anti-tumor effects of flavonoids from the ethnic medicine Docynia delavayi (Franch.) Schneid. and its possible mechanism. J Med Food 17: 787-794, 2014.

10. Ramesh E and Alshatwi AA: Naringin induces death receptor and mitochondria-mediated apoptosis in human cervical cancer (SiHa) cells. Food Chem Toxicol 51: 97-105, 2013.

11. Hu T, He XW, Jiang JG and Xu XL: Efficacy evaluation of a Chinese bitter tea (Ilex latifolia Thunb.) via analyses of its main components. Food Funct 5: 876-881, 2014.

12. Sak K: Characteristic features of cytotoxic activity of flavonoids on human cervical cancer cells. Asian Pac J Cancer Prev 15: 8007-8019, 2014

13. Luo M, Mo J, Yu Q, Zhou S, Ning R, Zhang Y, Su C, Wang H and Cui J: Wogonoside induces apoptosis in human non-small cell lung cancer A549 cells by promoting mitochondria dysfunction. Biomed Pharmacother 106: 593-598, 2018.

14. Li H, Hui H, Xu J, Yang H, Zhang X, Liu X, Zhou Y, Li Z, Guo $Q$ and Lu N: Wogonoside induces growth inhibition and cell cycle arrest via promoting the expression and binding activity of GATA-1 in chronic myelogenous leukemia cells. Arch Toxicol 90: 1507-1522, 2016.

15. Li Y, Tu M, Cheng C, Tian J, Zhang F, Deng Z, Li X, Li Z, Liu Y and Lei G: Wogonoside induces apoptosis in Bel-7402, a hepatocellular carcinoma cell line, by regulating Bax/Bcl-2. Oncol Lett 10: 1831-1835, 2015.

16. Xu Y, Lu X, Hu Y, Yang B, Tsui CK, Yu S, Lu L and Liang X Melatonin attenuated retinal neovascularization and neuroglial dysfunction by inhibition of HIF-1 $\alpha$-VEGF pathway in oxygen-induced retinopathy mice. J Pineal Res 64: e12473, 2018
17. Xu Y, Yang B, Hu Y, Lu L, Lu X, Wang J, Shu Q, Cheng Q, Yu S $\mathrm{Xu}$ F, et al: Secretion of down syndrome critical region 1 isoform 4 in ischemic retinal ganglion cells displays anti-angiogenic properties via NFATc1-dependent pathway. Mol Neurobiol 54: 6556-6571, 2017.

18. Livak KJ and Schmittgen TD: Analysis of relative gene expression data using real-time quantitative PCR and the 2(-Delta Delta $\mathrm{C}(\mathrm{T}))$ method. Methods 25: 402-408, 2001.

19. Kim C and Kim B: Anti-cancer natural products and their bioactive compounds inducing ER stress-mediated apoptosis: A Review. Nutrients 10: 1021, 2018.

20. Wang Y, Wang K, Jin Y and Sheng X: Endoplasmic reticulum proteostasis control and gastric cancer. Cancer Lett 449: 263-271, 2019.

21. Xu D, Liu L, Zhao Y, Yang L, Cheng J, Hua R, Zhang Z and Li Q: Melatonin protects mouse testes from palmitic acid-induced lipotoxicity by attenuating oxidative stress and DNA damage in a SIRT1-dependent manner. J Pineal Res: e12690, Aug 6 (Epub ahead of print).

22. Lee YS, Lee DH, Choudry HA, Bartlett DL and Lee YJ: Ferroptosis-induced endoplasmic reticulum stress: Cross-talk between ferroptosis and apoptosis. Mol Cancer Res 16: 1073-1076, 2018.

23. Lee H, Park MT, Choi BH, Oh ET, Song MJ, Lee J, Kim C, Lim BU and Park HJ: Endoplasmic reticulum stress-induced JNK activation is a critical event leading to mitochondria-mediated cell death caused by $\beta$-lapachone treatment. PLoS One 6: e21533, 2011.

24. Huang Y, Li X, Wang Y, Wang H, Huang C and Li J: Endoplasmic reticulum stress-induced hepatic stellate cell apoptosis through calcium-mediated JNK/P38 MAPK and Calpain/Caspase-12 pathways. Mol Cell Biochem 394: 1-12, 2014.

25. Wang X, Feng Y, Wang N, Cheung F, Tan HY, Zhong S, Li C and Kobayashi S: Chinese medicines induce cell death: The molecular and cellular mechanisms for cancer therapy. Biomed Res Int 2014: 530342, 2014.

26. Li HB and Chen F: Isolation and purification of baicalein, wogonin and oroxylin A from the medicinal plant Scutellaria baicalensis by high-speed counter-current chromatography. J Chromatogr A 1074: 107-110, 2005.

27. Huang ST, Wang CY, Yang RC, Chu CJ, Wu HT and Pang JH: Wogonin, an active compound in Scutellaria baicalensis, induces apoptosis and reduces telomerase activity in the HL-60 leukemia cells. Phytomedicine 17: 47-54, 2010.

28. Kim MS, Bak Y, Park YS, Lee DH, Kim JH, Kang JW, Song HH, Oh SR and Yoon DY: Wogonin induces apoptosis by suppressing E6 and E7 expressions and activating intrinsic signaling pathways in HPV-16 cervical cancer cells. Cell Biol Toxicol 29: 259-272, 2013.

29. Yang L, Zhang HW, Hu R, Yang Y, Qi Q, Lu N, Liu W, Chu YY, You QD and Guo QL: Wogonin induces G1 phase arrest through inhibiting Cdk4 and cyclin D1 concomitant with an elevation in p21Cip1 in human cervical carcinoma HeLa cells. Biochem Cell Biol 87: 933-942, 2009.

30. He F, Wang Q, Zheng XL, Yan JQ, Yang L, Sun H, Hu LN, Lin Y and Wang X: Wogonin potentiates cisplatin-induced cancer cell apoptosis through accumulation of intracellular reactive oxygen species. Oncol Rep 28: 601-605, 2012

31. Xu Y, Liu J, Wu Y, Guo Q, Sun H and Chen G: Natural products against hematological malignancies and identification of their targets. Sci China Life Sci 58: 1191-1201, 2015.

32. Bedoui S, Herold MJ and Strasser A: Emerging connectivity of programmed cell death pathways and its physiological implications. Nat Rev Mol Cell Biol: Sep 1, 2020 (Epub ahead of print).

33. Zheng L, Zheng J, Wu LJ and Zhao YY: Julibroside J8-induced HeLa cell apoptosis through caspase pathway. J Asian Nat Prod Res 8: 457-465, 2006.

34. Chen $M$ and Wang J: Initiator caspases in apoptosis signaling pathways. Apoptosis 7: 313-319, 2002

35. Gonzalez-Arzola K, Velazquez-Cruz A, Guerra-Castellano A, Guerra-Castellano A, Casado-Combreras MÁ, Pérez-Mejías G, Díaz-Quintana A, Díaz-Moreno I and De la Rosa MÁ: New moonlighting functions of mitochondrial cytochrome $\mathrm{c}$ in the cytoplasm and nucleus. FEBS Lett 593: 3101-3119, 2019.

36. Allan LA and Clarke PR: Apoptosis and autophagy: Regulation of caspase-9 by phosphorylation. FEBS J 276: 6063-6073, 2009.

37. Suen DF, Norris KL and Youle RJ: Mitochondrial dynamics and apoptosis. Genes Dev 22: 1577-1590, 2008. 
38. Martinou JC and Youle RJ: Mitochondria in apoptosis: Bcl-2 family members and mitochondrial dynamics. Dev Cell 21: 92-101, 2011.

39. Wang J, He W, Tsai PJ, Chen PH, Ye M, Guo J and Su Z: Mutual interaction between endoplasmic reticulum and mitochondria in nonalcoholic fatty liver disease. Lipids Health Dis 19: 72, 2020.

40. Jäger R, Bertrand MJ, Gorman AM, Vandenabeele P and Samali A: The unfolded protein response at the crossroads of cellular life and death during endoplasmic reticulum stress. Biol Cell 104: 259-270, 2012.

41. Clarke R, Cook KL, Hu R, Facey CO, Tavassoly I, Schwartz JL, Baumann WT, Tyson JJ, Xuan J, et al: Endoplasmic reticulum stress, the unfolded protein response, autophagy, and the integrated regulation of breast cancer cell fate. Cancer Res 72: 1321-1331, 2012.

42. Nishitoh $\mathrm{H}$ : CHOP is a multifunctional transcription factor in the ER stress response. J Biochem 151: 217-219, 2012.

43. Hammadi M, Oulidi A, Gackiere F, Katsogiannou M, Slomianny C, Roudbaraki M, Dewailly E, Delcourt P, Lepage G, Lotteau S, et al: Modulation of ER stress and apoptosis by endoplasmic reticulum calcium leak via translocon during unfolded protein response: Involvement of GRP78. FASEB J 27: 1600-1609, 2013.

44. Zhang K and Kaufman RJ: Signaling the unfolded protein response from the endoplasmic reticulum. J Biol Chem 279: 25935-25938, 2004.

45. Shen X, Zhang K and Kaufman RJ: The unfolded protein response-a stress signaling pathway of the endoplasmic reticulum. J Chem Neuroanat 28: 79-92, 2004.
46. Wang JR, Tanaka T, Zhang H, Kouno I and Jiang ZH: Formation and conformation of baicalin-berberine and wogonoside-berberine complexes. Chem Pharm Bull (Tokyo) 60: 706-711, 2012.

47. Xia B, Zhou Q, Zheng Z, Ye L, Hu M and Liu Z: A novel local recycling mechanism that enhances enteric bioavailability of flavonoids and prolongs their residence time in the gut. Mol Pharm 9: 3246-3258, 2012.

48. Dai JY, Yang JL and Li C: Transport and metabolism of flavonoids from Chinese herbal remedy Xiaochaihu-tang across human intestinal Caco-2 cell monolayers. Acta Pharmacol Sin 29: 1086-1093, 2008.

49. Shi R, Zhou H, Liu Z, Ma Y, Wang T, Liu Y and Wang C: Influence of coptis Chinensis on pharmacokinetics of flavonoids after oral administration of radix Scutellariae in rats. Biopharm Drug Dispos 30: 398-410, 2009.

50. Zhang Q, Ma YM, Wang ZT and Wang CH: Differences in pharmacokinetics and anti-inflammatory effects between decoction and maceration of Sanhuang Xiexin Tang in rats and mice. Planta Med 79: 1666-1673, 2013.

This work is licensed under a Creative Commons Attribution-NonCommercial-NoDerivatives 4.0 International (CC BY-NC-ND 4.0) License. 